\title{
Lowenstein-Jensen Medium
}

National Cancer Institute

\section{Source}

National Cancer Institute. Lowenstein-Jensen Medium. NCI Thesaurus. Code C85507.

A growth medium that is especially used for the cultivation of mycobacterium. It contains

malachite green, glycerol, asparagine, coagulated eggs, and mineral salts. 